\title{
Preface for the special issue: IMSD
}

\author{
Aki Mikkola • Werner Schiehlen
}

Received: 4 November 2011 / Accepted: 5 December 2011 / Published online: 3 January 2012

(C) Springer Science+Business Media B.V. 2011

The First Joint International Conference on Multibody System Dynamics (IMSD2010), held in May 2010 at the Lappeenranta University of Technology (LUT) in Finland, enabled the international multibody community to meet and exchange information and ideas on the theory and applications of multibody systems. It was sponsored by the ASME (American Society of Mechanical Engineers), IFToMM (International Federation for the Promotion of Mechanism and Machine Science), IUTAM (International Union of Theoretical and Applied Mechanics), KSME (Korean Society of Mechanical Engineers), and JSME (Japan Society of Mechanical Engineers). The conference, attended by 242 participants, featured more than 180 presentations, delivered by representatives of 29 countries.

In view of the exceptional works presented and the discussions that followed, which included many of the foremost international researchers in Multibody Dynamics, a selected number of authors were invited to submit manuscripts to the Multibody Systems Dynamics journal where they have undergone a strict peer-review process.

This issue of the Multibody Systems Dynamics journal presents six of these papers representing the range of topics addressed by Multibody Dynamics; vehicle dynamics, control and mechatronics, algorithms, integration codes, and software. These manuscripts suggest a trend towards theoretically and computationally challenging applications. We are confident that journal readers will find the contents of this issue informative and valuable in their activities related to multibody systems.

We would like to take this opportunity to thank the sponsors, organizers, and all participants of the IMSD2010 conference. The success of this First Joint International Conference on Multibody System Dynamics would not have been possible without

\footnotetext{
A. Mikkola (凶)

Department of Mechanical Engineering, Lappeenranta University of Technology, 53850 Lappeenranta, Finland

e-mail: aki.mikkola@lut.fi
}

W. Schiehlen

Institute of Engineering and Computational Mechanics, University of Stuttgart, 70569 Stuttgart, Germany 
their significant contributions. Finally, we are grateful to the manuscript reviewers, who gave priority to works produced after the IMSD2010 conference, and to the journal of Multibody System Dynamics for gathering these high-quality research papers together in the same issue and in this way representing the progress achieved by the IMSD2010.

\section{Guest Editors}

